\title{
Desempenho, qualidade de carcaça e carne de suínos alimentados com dietas contendo antioxidantes e ractopamina ${ }^{1}$
}

\section{Performance, carcass and meat quality of pigs fed diets with antioxidants and ractopamina}

\author{
Roberta Abrami Monteiro Silva ${ }^{1}$; Graziela Drociunas Pacheco ${ }^{2 *}$; \\ Piero da Silva Agostini ${ }^{3}$; Sylvia Luiza Vinokurovas ${ }^{4}$; Eduardo Raele de Oliveira ${ }^{1}$; \\ David Fernandes Gavioli"; Arturo Pardo Lozano'; Ana Maria Bridi²; \\ Caio Abércio da Silva
}

\section{Resumo}

\begin{abstract}
O objetivo do trabalho foi avaliar a utilização de aditivos antioxidantes associados ou não à ractopamina em rações de suínos em terminação. Utilizou-se 51 suínos, 27 machos castrados e 24 fêmeas, com peso médio inicial de $83,38 \mathrm{~kg}$. Foram estabelecidos três tratamentos experimentais, baseados na inclusão de dois complexos às rações: Complexo 1 ( $4 \mathrm{~g}$ de vitamina $\mathrm{E}+1 \mathrm{~g}$ de vitamina $\mathrm{C} / \mathrm{kg}$ do produto) e Complexo $2(0,2 \mathrm{~g}$ de ractopamina $+4 \mathrm{~g}$ de vitamina $\mathrm{E}+2 \mathrm{~g}$ de vitamina $\mathrm{C} / \mathrm{kg}$ de produto $)$, definindo: ração controle (isenta dos Complexos); ração controle + Complexo $1(0,1 \%)$; e ração controle + Complexo $2(0,05 \%)$. $\mathrm{O}$ delineamento experimental foi em blocos casualizados, num arranjo fatorial $3 \times 2$ (3 tratamentos e 2 sexos). Verificou-se diferença $(\mathrm{P}<0,05)$ para o consumo diário de ração, conversão alimentar, peso de carcaça quente, peso de carcaça fria a favor do tratamento com ractopamina. Os tratamentos que continham vitamina $\mathrm{E}$ apresentaram maiores valores da vitamina na carne $(\mathrm{P}<0,05)$, e também menores $(\mathrm{P}<0,05)$ valores de oxidação e taxa de marmoreio. A inclusão de ractopamina, juntamente com os antioxidantes testados, resulta em melhora nas características de desempenho e carcaça. A suplementação com o complexo antioxidante, isoladamente, melhora parâmetros relacionados à qualidade da carne.

Palavras-chave: Beta-adrenérgico, músculo, oxidação lipídica, tecido adiposo, vitamina
\end{abstract}

\begin{abstract}
The objective was evaluated the effects of the use of additives antioxidants associated or not with ractopamine in feed for finishing pigs. Were used 51 crossbred pigs, 27 barrows and 24 females with initial weight of $83.38 \mathrm{~kg}$. Three experimental treatments were established based on the inclusion of two complexes to feed: complex 1 ( $4 \mathrm{~g}$ de vitamin $\mathrm{E}+1 \mathrm{~g}$ de vitamin $\mathrm{C} / \mathrm{kg}$ of product) and complex 2 ( $0.2 \mathrm{~g}$ de ractopamine $+4 \mathrm{~g}$ de vitamin $\mathrm{E}+2 \mathrm{~g}$ de vitamin $\mathrm{C} / \mathrm{kg}$ of product), defining the ration control (free of complexes), ration control + complex $1(0.1 \%)$ and ration control + complex $2(0.05 \%)$. The experimental design was blocked randomically, presenting a factorial model $3 \times 2$ ( 3 treatments and 2 sexes). Were observed difference $(\mathrm{P}<0.05)$ for daily feed intake, feed, hot and cold carcass weight to
\end{abstract}

\footnotetext{
${ }^{1}$ Discentes de Doutorado em Ciência Animal, Universidade Estadual de Londrina, UEL, Londrina, PR. E-mail: ro_abrami@ hotmail.com; duraele@yahoo.com.br; setaarturo@hotmail.com

2 Profs. Drs. do Dept ${ }^{\circ}$ de Zootecnia, CCA, UEL, Londrina, PR. E-mail: grazivetuel@yahoo.com.br; ambridi@uel.br; casilva@uel.br

${ }^{3}$ Discente de Doutorado em Produção Animal, Dept ${ }^{\circ}$ de Ciência Animal e dos Alimentos da Universidade Autônoma de Barcelona, UAB, Espanha. E-mail: pieroagostini@hotmail.com

${ }^{4}$ Discentes de Mestrado em Ciência Animal, UEL, Londrina, PR. E-mail: luzinhavino@yahoo.com.br; davidgavioli@hotmail.com

* Autor para correspondência
} 
the treatment with ractopamine. The values of vitamin $\mathrm{E}$ in meat were higher $(\mathrm{P}<0.05)$ in muscle of animals in groups receiving the vitamin. There was a difference $(\mathrm{P}<0.05)$ in the values of oxidation and marbling in the treatments with antioxidant. The inclusion of ractopamine, with the antioxidants, resulted in improvement in performance and carcass characteristics, and supplementation with the antioxidant, alone, showed improvement in parameters related to meat quality.

Key words: Beta-adrenergic, fat tissue, lipid oxidation, muscular tissue, vitamin

\section{Introdução}

A qualidade e a segurança dos alimentos representam uma das características mais exigidas pelo mercado consumidor atualmente. Neste sentido, estes conceitos estão bem sedimentados na cadeia da carne suína, sendo foco a produção de animais precoces, eficientes e que apresentem carcaças com elevada relação carne: gordura associada a um ótimo padrão de qualidade.

Do ponto de vista qualitativo e de segurança alimentar, o uso de antioxidantes através da suplementação das rações animais, corresponde a uma das ferramentas para atingir esses objetivos, minimizando a oxidação lipídica, que é uma das principais causas de deterioração da carne e de seus subprodutos (SOARES, 2009).

Os antioxidantes mais utilizados na produção de carnes são a vitamina E e o ácido ascórbico (vitamina C). Segundo Morrissey et al. (1998), o ácido ascórbico, quando suplementado na dieta animal, aumenta a ação da vitamina E. Seu efeito benéfico na prevenção da oxidação lipídica, contudo, ainda é questionável. Há poucos estudos sobre a sua ação e o requerimento deste na dieta de animais de produção. Morrissey et al. (1998) provou que a vitamina E, especialmente quando incorporada à ração de animais, é depositada nas membranas celulares, sendo mais eficiente na prevenção da oxidação de lipídios do que qualquer outro antioxidante.

Segundo o NRC (1998), a necessidade de vitamina $\mathrm{E}$ no final do crescimento corporal para suínos é de $11 \mathrm{mg} / \mathrm{kg}$ de ração. Entretanto, quando a vitamina E é suplementada em níveis maiores (100 a $200 \mathrm{mg} / \mathrm{kg}$ de ração) é verificado um efeito antioxidante, aumentando o prazo de validade da carne (MORRISSEY et al., 1998; SOUZA, 2001; RADCLIFFE, 2004).

No aspecto produtivo a suinocultura também recorre a outros recursos nutricionais que promovem um maior ganho em músculo em detrimento da gordura. Neste aspecto, destaca-se a ractopamina, um aditivo repartidor de nutrientes, beta-adrenérgico, classificada como um promotor de crescimento (BRIDI et al., 2006). A substância age modificando o metabolismo animal, melhorando os índices de desempenho e as características de carcaça, direcionando os nutrientes para funções zootécnicas que são desejáveis para o produtor e o consumidor (BRIDI; SILVA; SHIMOKOMAKI, 2002).

Aractopamina é administrada nas rações de suínos em fase de terminação, no período anterior ao abate e em animais que já tenham atingido a maturidade, ou seja, quando a capacidade de retenção das proteínas começa a ser menor. Neste momento associa-se que os efeitos dos agonistas beta-adrenérgicos sejam mais evidentes (MOLONEY; BEERMMAN, 1996; AGOSTINI et al., 2008).

O presente trabalho teve por objetivo avaliar dois complexos comerciais contendo antioxidantes (vitamina $\mathrm{E}$ e vitamina $\mathrm{C}$ ) associados ou não à ractopamina, frente à promoção dos aspectos quantitativos e qualitativos de interesse na cadeia suinícola, destacando-se as características de desempenho, carcaça, carne e suas relações com alguns parâmetros sanguíneos.

\section{Material e Métodos}

O experimento foi conduzido no Setor de Suinocultura da Fazenda Escola da Universidade Estadual de Londrina. 
Foram utilizados 51 suínos mestiços (Landrace X Large White), sendo 27 machos castrados e 24 fêmeas, com a mesma idade (132 dias) e peso médio inicial de $83,38 \pm 10,82 \mathrm{~kg}$. Foram utilizadas nove baias para os machos ( 3 animais por baia) e nove para as fêmeas (sendo seis baias com 3 animais e três, uma de cada tratamento, com 2 animais). Os animais foram alojados em instalações de alvenaria e piso compacto com $3 \mathrm{~m}^{2}$. Durante o período experimental (28 dias) os animais receberam água e ração à vontade.

O delineamento experimental utilizado foi em blocos ao acaso num arranjo fatorial com 3 tratamentos e 2 sexos. Os animais foram blocados de acordo com o peso inicial, sendo divididos em leves, intermediários e pesados. Para o teste de desempenho cada repetição foi definida por uma baia, composta por animais do mesmo gênero.

Foram definidas três rações distintas, baseadas na inclusão de 2 complexos de aditivos: complexo
1 (4g de vitamina $\mathrm{E}+1 \mathrm{~g}$ de vitamina $\mathrm{C} / \mathrm{kg}$ do produto) e complexo 2 (0,2g de ractopamina $+4 \mathrm{~g}$ de vitamina $\mathrm{E}+2 \mathrm{~g}$ de vitamina $\mathrm{C} / \mathrm{kg}$ de produto), definindo: ração controle (isenta dos complexos); ração controle + complexo $1(0,1 \%)$; e ração controle + complexo $2(0,05 \%)$. As rações controle + complexo 1 e controle + complexo 2 apresentaram concentrações finais de 400 $\mathrm{mg}$ de vitamina $\mathrm{E}+100 \mathrm{mg}$ de vitamina $\mathrm{C} / \mathrm{kg}$ de ração, e $200 \mathrm{mg}$ de vitamina $\mathrm{E}+100 \mathrm{mg}$ de vitamina $\mathrm{C}+10$ ppm de ractopamina $/ \mathrm{kg}$ de ração, respectivamente. As rações eram isonutrientes, sendo formuladas visando atender as exigências previstas pela genética, atendendo no mínimo as recomendações nutricionais estabelecidas pelo NRC (1998).

Os ingredientes, a composição percentual e os valores calculados das rações experimentais encontram-se na Tabela 1 .

Tabela 1. Composição percentual, química e energética das rações experimentais.

\begin{tabular}{lccc}
\hline Ingredientes (kg) & Ração Controle & Ração Controle + Complexo $1^{4}$ & Ração Controle + Complexo $2^{5}$ \\
\hline Milho & 72,84 & 72,84 & 72,84 \\
Farelo de soja & 22,60 & 22,60 & 22,60 \\
Óleo de Soja & 1,49 & 1,49 & 1,49 \\
Núcleo único suínos $^{1}$ & 2,50 & 2,50 & 2,50 \\
L-Lisina-HCl & 0,47 & 0,47 & 0,47 \\
Inerte (caulim) & 0,1 & - & 0,05 \\
Complexo 1 $^{2}$ & - & 0,10 & - \\
Complexo 2 $^{3}$ & - & - & 0,05 \\
\hline Valores calculados & & & \\
\hline Proteína bruta (\%) & 16,71 & 16,71 & 16,71 \\
Extrato etéreo (\%) & 4,31 & 4,31 & 2,31 \\
Fibra bruta (\%) & 2,76 & 2,76 & 2,76 \\
Matéria mineral (\%) & 2,43 & 2,43 & 2,43 \\
Cálcio (\%) & 0,65 & 0,65 & 0,65 \\
Fósforo total (\%) & 0,48 & 0,48 & 0,48 \\
Energia Met. (Kcal/kg) & 3296,00 & 3296,00 & 3296,00 \\
Lisina total (\%) & 1,17 & 1,17 & 1,17 \\
\hline
\end{tabular}

${ }^{1}$ Composição do núcleo único suínos por kg de produto: vit.A, 239.000 UI; vit.B12, 538 mcg; vit.D3, 66.000 UI; vit.E, 517 mg; vit.K3, $60 \mathrm{mg}$; ácido fólico, $32 \mathrm{mg}$; ácido pantotênico, $254 \mathrm{mg}$; biotina, 1,1 mg; niacina, $422 \mathrm{mg}$; piridoxina, $41 \mathrm{mg}$; riboflavina, 90 mg; tiamina, $33 \mathrm{mg}$; colina, 4 g; promotor de crescimento, 2595 mg; Ca, 231 g; Co, 5,5 mg; Cu, 5000 mg; Fe, 2760 mg; F, 881 mg; P, 59 g; I, 43 mg; Mn, 1310 mg; Se, 8,46 mg; Na, 50 g; Zn, 3720 mg.

${ }^{2}$ Complexo $1=4 \mathrm{~g}$ de vitamina $\mathrm{E}+1 \mathrm{~g}$ de vitamina $\mathrm{C} / \mathrm{kg}$ do produto.

${ }^{3}$ Complexo $2=0,2 \mathrm{~g}$ de ractopamina $+4 \mathrm{~g}$ de vitamina $\mathrm{E}+2 \mathrm{~g}$ de vitamina $\mathrm{C} / \mathrm{kg}$ de produto.

${ }^{4}$ Ração controle + complexo 1 = concentrações finais de $400 \mathrm{mg}$ de vitamina $\mathrm{E}+100 \mathrm{mg}$ de vitamina $\mathrm{C} / \mathrm{kg}$ de ração.

${ }^{5}$ Ração controle + complexo 2 = concentrações finais de $200 \mathrm{mg}$ de vitamina $\mathrm{E}+100 \mathrm{mg}$ de vitamina $\mathrm{C}+10 \mathrm{ppm}$ de ractopamina/ $\mathrm{kg}$ de ração, respectivamente.

Fonte: Elaboração dos autores. 
Foram avaliados os parâmetros de desempenho ganho diário de peso (GDP), consumo diário de ração (CDR) e conversão alimentar (CA).

Aos 21 dias de experimento os animais foram submetidos à coleta de sangue da veia cava cranial utilizando-se agulhas descartáveis de 40 x 12 mm. Para a determinação da concentração sérica do ácido láctico, cortisol e creatina fosfoquinase, o sangue foi coletado em tubos sem anti-coagulante, que foram submetidos à centrifugação a $2000 \mathrm{rpm}$ por 10 minutos. $\mathrm{O}$ soro obtido foi transferido para microtubos (eppendorf) de 1,5 mL, identificados e conservados a $-20^{\circ} \mathrm{C}$ para posterior análise em laboratório clínico.

Após o período experimental de 28 dias foi realizado o manejo pré-abate, retirando a ração 12 horas antes do embarque, permanecendo os animais sob dieta hídrica até o abate.

Os suínos foram abatidos com idade média de 160 dias e peso médio de $111,43 \pm 12,14 \mathrm{~kg}$. $\mathrm{O}$ processo de abate consistiu primeiramente na insensibilização elétrica (Petrovina ${ }^{\circledR}$ IS 2000 com dois eletrodos), utilizando-se 350 volts e 1,3 ampères. A sangria foi realizada por meio do corte dos grandes vasos do pescoço, com os animais na posição vertical, suspensos pelo membro posterior. Após o abate, escaldagem e evisceração, as carcaças foram divididas ao meio longitudinalmente, pesadas para a obtenção do peso de carcaça quente (PCQ) e resfriadas à temperatura de $2 \pm 1{ }^{\circ} \mathrm{C}$, por 24 horas, na câmara de resfriamento do frigorífico.

Após o período de 24 horas, as carcaças foram avaliadas individualmente de acordo com as orientações da ABCS (1973). Foram obtidos os dados de peso da carcaça fria (PCF), rendimento de carcaça (RC), comprimento de carcaça (CC), conformação (CONF) e, cada meia carcaça esquerda foi seccionada na altura da última costela onde foram realizadas as medidas de área de olho de lombo (AOL), profundidade do músculo (PM) Longissimus dorsi e espessura de toucinho(ET). Com essas medidas foi possível calcular a quantidade de carne magra na carcaça (QCMC). Para as análises de carcaça e qualidade de carne, cada animal foi considerado uma unidade experimental.

O pH da carne foi medido no músculo Longissimus dorsi, na altura da última costela, aos 45 minutos após o abate ( $\mathrm{pH}$ inicial) e após 24 horas de resfriamento ( $\mathrm{pH}$ final) a aproximadamente $2 \pm$ $1^{\circ} \mathrm{C}$.

Após 24 horas de resfriamento, foi retirada de cada meia carcaça esquerda uma amostra do músculo Longissimus dorsi de aproximadamente $20 \mathrm{~cm}$. De cada lombo retirou-se a gordura adjacente e então foram coletadas 5 amostras de aproximadamente $2,5 \mathrm{~cm}$ de espessura.

Dessas cinco amostras do lombo de cada animal, uma foi utilizada para avaliação da cor (valores de $a^{*}, b^{*}$ e L*), marmoreio e estimou-se a perda de água por gotejamento (PAG).

A cor foi medida como o aparelho colorímetro portátil Minolta ${ }^{\circledR}$ CR10. Os componentes $\mathrm{L}^{*}$ (luminosidade), a* (componente vermelho-verde) e $b^{*}$ (componente amarelo-azul) foram expressos no sistema de cor CIELAB. Através dessas três leituras foram também definidos o croma e a tonalidade da carne. Estas mesmas amostras foram utilizadas para a avaliação subjetiva da taxa de marmoreio onde foram atribuídas notas de 1 a $5(1=$ traços de marmoreio e $5=$ marmoreio abundante) (BRIDI; SILVA, 2009).

A capacidade de retenção de água da carne foi avaliada através da perda de água por gotejamento, segundo a técnica descrita por Boccard et al. (1981).

A análise da oxidação lipídica foi realizada 30 dias após o abate. O método utilizado para a análise foi o Indicativo de Substâncias Reativas ao Ácido Tiobarbitúrico (TBARS), segundo Tarladgis, Pearson e Dugan Júnior (1964) modificado por Crackel et al. (1988).

As amostras destinadas à análise de maciez foram congeladas por 90 dias e pesadas logo que retiradas do freezer e após o desgelo por 24 horas 
na temperatura de $2 \pm 2{ }^{\circ} \mathrm{C}$, obtendo assim, pela diferença desses dois pesos, os valores de perda de líquido por descongelamento (PLD). Essas amostras foram utilizadas também para a análise de perda de líquido na cocção, que foi obtida pela diferença de peso da amostra descongelada e após o cozimento em forno pré-aquecido a $180{ }^{\circ} \mathrm{C}$, até alcançarem a temperatura interna de aproximadamente $71{ }^{\circ} \mathrm{C}$ (BRIDI; SILVA, 2009).

Depois da cocção as amostras foram resfriadas à temperatura ambiente e acondicionadas em uma geladeira por 24 horas a $2 \pm 2{ }^{\circ} \mathrm{C}$. Após esse período de 24 horas foram retiradas de cada amostra, de 5 a 6 sub-amostras de $2,5 \mathrm{~cm}$ de comprimento e $1 \mathrm{~cm}$ de diâmetro, utilizando-se um amostrador de aço da forma cilíndrica. A força de cisalhamento foi tomada perpendicularmente à orientação das fibras musculares com a lâmina Warner-Bratzler adaptada no texturômetro Stable Mycro Systems TA-XT2i (BOUTON; HARRIS; SHORTHOSE, 1971).

O Perfil de Ácidos Graxos das carnes foi analisado através da técnica de Bligh e Dyer (1959).

Para a análise de vitamina $E$, as amostras foram analisadas por cromatografia líquida de alta eficiência (HPLC) (BRUBACHER; MULLERMULOT; SOUTHGATE, 1985).

Os dados relativos aos tratamentos foram submetidos à análise de variância e as médias comparadas pelo teste de Tukey, utilizando-se o programa SAEG (UFV, 1997).

\section{Resultados e Discussão}

Os resultados referentes aos parâmetros de desempenho, carcaça e qualidade da carne estão apresentados na Tabela 2. Houve diferença $(\mathrm{P}<0,05)$ a favor do grupo tratado com a associação dos antioxidantes e ractopamina (ração controle + complexo 2) em relação ao grupo que recebeu somente antioxidantes (ração controle + complexo 1) para os parâmetros ganho diário de peso e conversão alimentar, indicando que a ractopamina pode ter influenciado nos resultados obtidos. Da mesma forma, Girão et al. (2008), trabalhando com suínos que receberam ractopamina, durante 14 ou 28 dias, independentemente do nível de suplementação, apresentaram maior peso final, maior ganho de peso médio diário e melhor conversão alimentar. Cannon et al. (1996), Hoving-Bolink et al. (1998) e Onibi et al. (1998), que também trabalharam com suplementação de vitamina $\mathrm{E}$ na ração de suínos em crescimento e terminação com concentrações de $100 \mathrm{mg}$ vit. E/kg ração, $8 \mathrm{mg}$ vit. E/kg ração e 200 $\mathrm{mg}$ vit. $\mathrm{E} / \mathrm{kg}$ ração, repectivamente, não observaram influência dos níveis de vitamina E sobre o ganho de peso e conversão alimentar dos animais.

Quanto aos parâmetros séricos, não foi observada diferença $(\mathrm{P}>0,05)$ para os tratamentos nem para os gêneros. Há de se considerar, entretanto, que embora se constate uma diferença numérica importante entre os valores de creatinina fosfoquinase entre os tratamentos, não se identificou significância entre estes $(\mathrm{P}>0,05)$, sendo atribuída à grande variação encontrada nos dados (alto coeficiente de variação).

Alguns trabalhos realizados utilizando-se ractopamina em suínos e bubalinos elucidam que há aumento nos níveis sanguíneos de lactato, constituindo dessa forma um forte indicador da ocorrência de glicogenólise muscular com a utilização desse beta-agonista. (PALERMO-NETO, 2002). 
Tabela 2. Médias das características: CDR (consumo diário de ração), GDP (ganho diário de peso), CA (conversão alimentar), creatina fosfoquinase (CK), cortisol e ácido lático, peso de carcaça quente (PCQ), peso de carcaça resfriada (PCR), rendimento de carcaça (RC), comprimento de carcaça (CC), conformação (CONF), espessura de toucinho (ET), quantidade de carne magra na carcaça (QCMC), $\mathrm{pH}$ inicial e final, cor ( $\mathrm{a}^{*}, \mathrm{~b}^{*} \mathrm{e} \mathrm{L}^{*}$ ), croma e tonalidade, expressa em graus, perda de água por gotejamento (PAG), TBARs, marmoreio, perda de líquido no descongelamento (PLD), perda de líquido na cocção (PLC) e força de cisalhamento (FC) e vitamina $\mathrm{E}$ de suínos de diferentes gêneros submetidos a diferentes tratamentos.

\begin{tabular}{|c|c|c|c|c|c|c|}
\hline \multirow[b]{2}{*}{ Parâmetros } & \multicolumn{3}{|c|}{ Tratamentos } & \multicolumn{2}{|c|}{ Gêneros } & \multirow[b]{2}{*}{$\begin{array}{l}\text { C.V. } \\
(\%)\end{array}$} \\
\hline & Controle $^{1}$ & $\begin{array}{c}\text { Controle }+ \\
\text { Complexo } 1^{2}\end{array}$ & $\begin{array}{c}\text { Controle }+ \\
\text { Complexo } 2^{3}\end{array}$ & $\begin{array}{l}\text { Machos } \\
\text { castrados }\end{array}$ & Fêmeas & \\
\hline CDR (kg) & 2,86 & 3,01 & 3,02 & 3,07 & 2,86 & 8,20 \\
\hline GDP (kg) & $0,94 \mathrm{ab}$ & $0,91 \mathrm{~b}$ & $1,10 \mathrm{a}$ & 0,98 & 0,98 & 11,09 \\
\hline $\mathrm{CA}$ & $3,02 \mathrm{ab}$ & $3,33 \mathrm{a}$ & $2,74 \mathrm{~b}$ & 3,13 & 2,93 & 7,80 \\
\hline CK (u/l) & 2166,6 & 1608,5 & 3314,3 & 2762,1 & 1964,1 & 141,3 \\
\hline Cortisol (ug/dL) & 3,73 & 4,00 & 3,89 & 4,28 & 3,47 & 46,83 \\
\hline Ác. lático $(\mathrm{mmol} / \mathrm{L})$ & 4,39 & 4,34 & 4,81 & 4,72 & 4,30 & 39,35 \\
\hline PCQ (kg) & $83,05 \mathrm{~b}$ & $84,01 \mathrm{~b}$ & 87,93 a & 86,05 & 83,82 & 5,24 \\
\hline PCR (kg) & $80,98 \mathrm{~b}$ & $82,00 \mathrm{~b}$ & 85,79 a & 83,97 & 81,75 & 5,31 \\
\hline $\mathrm{RC}(\%)$ & 75,39 & 76,48 & 72,35 & 76,52 & 72,73 & 14,20 \\
\hline $\mathrm{CC}(\mathrm{cm})$ & 94,91 & 94,68 & 94,81 & 95,32 & 94,21 & 2,52 \\
\hline CONF (1-3) & 1,91 & 1,94 & 2,15 & 2,00 & 2,00 & 22,29 \\
\hline ET (1-3) & 14,23 & 13,49 & 15,09 & $16,59 \mathrm{~b}$ & $11,66 \mathrm{a}$ & 25,23 \\
\hline QCMC (kg) & 60,24 & 60,41 & 59,84 & $58,41 \mathrm{~b}$ & $62,14 \mathrm{a}$ & 4,61 \\
\hline $\mathrm{pH}$ inicial & 6,24 & 6,17 & 6,06 & 6,08 & 6,24 & 5,82 \\
\hline pH final & 5,59 & 5,68 & 5,64 & 5,68 & 5,60 & 3,19 \\
\hline$a^{*}$ & 2,59 & 2,15 & 1,69 & 1,97 & 2,34 & 69,23 \\
\hline$b^{*}$ & 7,83 & 7,89 & 7,32 & 7,49 & 7,89 & 16,08 \\
\hline $\mathrm{L}^{*}$ & 57,01 & 57,38 & 58,06 & 56,56 & 58,52 & 5,44 \\
\hline Croma & 8,33 & 8,26 & 7,56 & 7,83 & 8,30 & 19,42 \\
\hline Tonag & 73,26 & 75,73 & 77,00 & 76,32 & 74,22 & 10,39 \\
\hline PAG & 4,02 & 4,31 & 3,36 & $3,47 \mathrm{a}$ & 4,33 & 29,08 \\
\hline TBARS & $0,13 \mathrm{a}$ & $0,09 \mathrm{~b}$ & $0,08 \mathrm{~b}$ & 0,10 & 0,10 & 28,76 \\
\hline Marmoreio & $1,41 \mathrm{~b}$ & $1,59 \mathrm{ab}$ & $1,94 \mathrm{a}$ & 1,67 & 1,62 & 32,14 \\
\hline PLD & 8,99 & 7,33 & 8,70 & 8,66 & 8,03 & 25,50 \\
\hline PLC & 25,17 & 24,60 & 24,19 & 24,82 & 24,49 & 13,99 \\
\hline FC (kgf) & 4,15 & 4,13 & 4,47 & 4,12 & 4,38 & 20,89 \\
\hline Vit E (mg/kg) & $0,12 \mathrm{~b}$ & $0,34 \mathrm{a}$ & $0,27 \mathrm{ab}$ & 0,23 & 0,26 & 37,32 \\
\hline
\end{tabular}

Médias seguidas de letras maiúsculas diferentes nas linhas e letras minúsculas diferentes nas colunas indicam diferença no teste de Tukey $(\mathrm{P}<0,05)$.

${ }^{1}$ Ração controle (isenta dos complexos), ${ }^{2}$ Ração controle + complexo $1(400 \mathrm{mg}$ de vitamina E + $100 \mathrm{mg}$ de vitamina C/ kg de ração) e ${ }^{3}$ Ração controle + complexo 2 (200 mg de vitamina E + $100 \mathrm{mg}$ de vitamina C + 10 ppm de ractopamina $/ \mathrm{kg}$ de ração).

Fonte: Elaboração dos autores.

Segundo Marchant-Forde (2003), após a utilização da ractopamina durante quatro semanas em animais de terminação, observou-se, com relação aos níveis de cortisol circulantes, que não houve diferença entre os tratamentos quer antes ou depois do transporte dos animais ao abatedouro.
Para as características de carcaça somente foram verificadas diferenças $(\mathrm{P}<0,05)$ para os pesos de carcaça quente e carcaça resfriada, favorecendo o grupo que recebeu ractopamina (ração controle + complexo 2). Em relação ao gênero, as fêmeas apresentaram melhores resultados para os 
parâmetros espessura de toucinho e quantidade de carne magra na carcaça.

Como Cardoso e Stock (1996) explicam, a diminuição da gordura na carcaça é acompanhada por um aumento do teor em água que está associado ao correspondente incremento de proteína. Isto representa um dos principais fatores que justificam o aumento do ganho de peso da carcaça e que pode explicar o melhor rendimento de carcaça observada neste trabalho.

Os resultados foram semelhantes aos observados por Carr et al. (2005), que não observaram diferenças na espessura de toucinho e no comprimento de carcaça entre animais tratados com ractopamina e controle.

Cannon et al. (1996) não observaram diferenças significativas nas características de carcaça em suínos suplementados com vitamina E. Todavia, Cheah, Cheah e Krausgrille (1995) e Hasty et al. (2002) observaram aumento na quantidade de carne magra e redução na espessura de toucinho na carcaça de suínos suplementados com vitamina E.

Para os parâmetros área de olho de lombo (AOL) e profundidade de músculo (PM) (Tabela 3 ), houve interação entre os tratamentos e gêneros. Em relação aos tratamentos, para os dois parâmetros, o grupo que recebeu ração com antioxidante associado à ractopamina (ração controle + complexo 2) apresentou melhores resultados. Isso ocorre, pois a ractopamina age como um modificador do metabolismo animal, alterando a partição de nutrientes desviando e promovendo o crescimento e a deposição de tecido magro e reduzindo o teor de gordura na carcaça de suínos em crescimento e terminação (BRIDI; NICOLAIEWSKY; RUBENSAN, 2003). Budiño et al. (2005) também observaram aumento da área de olho de lombo em suínos tratados com ractopamina. Em relação aos gêneros, foi encontrada diferença $(\mathrm{P}<0,05)$ somente para os animais que receberam ração controle, sendo que as fêmeas apresentaram-se melhores para as características.

Tabela 3. Interação entre diferentes tratamentos e sexos para os parâmetros área de olho de lombo (AOL) e profundidade de músculo (PM) de suínos.

\begin{tabular}{lcccc}
\hline Parâmetros & \multicolumn{3}{c}{ Tratamentos } & CV (\%) \\
\hline AOL $\left(\mathrm{cm}^{2}\right)$ & Ração Controle $_{1}$ & Ração Controle + Complexo 1 & Ração Controle + Complexo 23 \\
Machos castrados & $40,22 \mathrm{bB}$ & $42,91 \mathrm{aB}$ & $45,78 \mathrm{aA}$ & 9,45 \\
Fêmeas & $45,68 \mathrm{aAB}$ & $41,90 \mathrm{aB}$ & $47,22 \mathrm{aA}$ & 7,75 \\
PM (mm) & & & & \\
Machos castrados & $60,12 \mathrm{bB}$ & $61,74 \mathrm{aB}$ & $70,58 \mathrm{aA}$ & 9,65 \\
Fêmeas & $70,93 \mathrm{aA}$ & $64,40 \mathrm{aA}$ & $68,50 \mathrm{aA}$ & 8,22 \\
\hline
\end{tabular}

Médias seguidas de letras maiúsculas diferentes nas linhas e letras minúsculas diferentes nas colunas indicam diferença no teste de Tukey $(\mathrm{P}<0,05)$.

${ }^{1}$ Ração controle (isenta dos complexos), ${ }^{2}$ Ração controle + complexo 1(400 mg de vitamina E + $100 \mathrm{mg}$ de vitamina C/ kg de ração) e ${ }^{3}$ Ração controle + complexo 2 (200 mg de vitamina $\mathrm{E}+100 \mathrm{mg}$ de vitamina $\mathrm{C}+10 \mathrm{ppm}$ de ractopamina $/ \mathrm{kg}$ de ração).

Fonte: Elaboração dos autores.

Para os parâmetros de qualidade de carne ( $\mathrm{pH}$ inicial, $\mathrm{pH}$ final, cor $\mathrm{a}^{*}$, cor $\mathrm{b}^{*}$, cor $\mathrm{L}^{*}$, croma e tonalidade) não foram observadas diferenças $(\mathrm{P}>0,05)$ entre os tratamentos. Sabe-se que antioxidantes, tais como a vitamina $C$ e a vitamina $E$ são efetivos não só na redução da oxidação lipídica, como também prevenindo a oxidação da mioglobina, o que evita a descoloração em carnes frescas e congeladas (EIKELENBOOM et al., 2000). Entre os gêneros houve diferença $(\mathrm{P}<0,05)$ nos valores de $\mathrm{L}^{*}$ a favor dos machos, visto que 
as fêmeas apresentaram carnes mais claras o que é desfavorável no aspecto de qualidade de carne, por ser uma das medidas que indicam carnes PSE (pálida, mole e exudativa).

Para os resultados de oxidação (TBARS), os grupos que receberam ração com antioxidante (ração controle + complexo 1 e ração controle + complexo 2) apresentaram melhores resultados em relação ao grupo que recebeu ração controle.

A Figura 1 mostra que os animais que receberam antioxidante na ração apresentaram carnes com menores índices de oxidação (menores valores de
TBARS) e dados mais homogêneos em relação ao grupo que recebeu ração controle, o qual apresentou maior dispersão nos dados e maiores valores de TBARS. O baixo nível de TBARS presentes nos grupos que receberam suplementação com antioxidante se deve ao fato de que a vitamina $\mathrm{E}$ neutraliza radicais livres e interrompe a cadeia de reações oxidativas, atuando como um escudo protetor ao redor de cada célula e reduzindo os danos aos tecidos (RADCLIFFE, 2004; PENNY, 2004). Segundo Araújo (2004), a vitamina E tem sua ação mais pronunciada na gordura animal, especialmente na presença de sinergistas.

Figura 1. Valores de TBARs encontrados nas carnes de suínos submetidos aos tratamentos: $1=$ Ração controle (isenta dos complexos), 2= Ração controle + complexo 1(400 mg de vitamina $\mathrm{E}+100 \mathrm{mg}$ de vitamina $\mathrm{C} / \mathrm{kg}$ de ração) e $3=$ Ração controle + complexo 2 (200 mg de vitamina $\mathrm{E}+100 \mathrm{mg}$ de vitamina $\mathrm{C}+10 \mathrm{ppm}$ de ractopamina $/ \mathrm{kg}$ de ração).

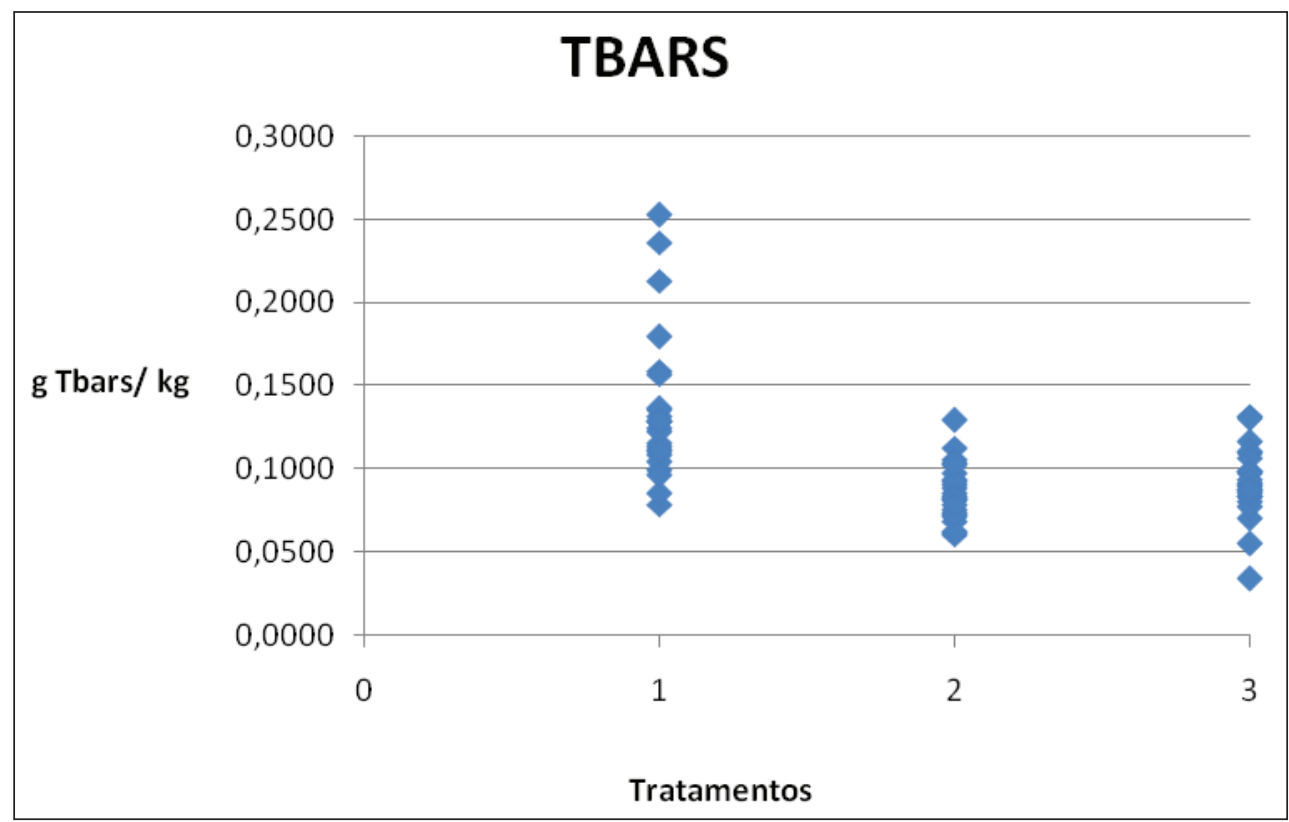

Fonte: Elaboração dos autores.

Em relação ao marmoreio, os resultados encontrados foram a favor do grupo tratado com a associação da ractopamina ao antioxidante (ração controle + complexo 2), porém não houve diferença $(\mathrm{P}>0,05)$ em relação ao grupo tratado com a ração contendo somente antioxidante (ração controle + complexo 1).
$\mathrm{Na}$ perda de água por gotejamento houve diferença $(\mathrm{P}<0,05)$ entre os gêneros, sendo que os machos apresentaram uma menor perda.

Bridi et al. (2006), utilizando $10 \mathrm{ppm}$ de ractopamina na ração de suínos em fase de terminação, não encontraram alterações nos valores de $\mathrm{pH}$ inicial e final da carne, no grau de marmoreio, 
na maciez, na perda de água, coloração e frequência de PSE da carne.

Quanto às características de perda de água no descongelamento e cocção não ocorreram diferenças entre os tratamentos $(\mathrm{P}>0,05)$. Isso pode ser explicado pela preservação da integridade da membrana das células musculares devido ao uso dos antioxidantes (as vitaminas C e E), e pela não alteração de $\mathrm{pH}$ entre os tratamentos, já que a quantidade de água retida na carne está diretamente influenciada pelos valores de $\mathrm{pH}$ inicial e pH final. Alterações no pH, como a diminuição brusca, juntamente com altas temperaturas das carcaças ocasionam a desnaturação das proteínas e consequentemente aumentam o extravasamento de água e pigmentos (LAWRIE, 2005).

Os resultados estão de acordo com os encontrados por Bridi et al. (2006), que não acharam diferenças $(\mathrm{P}>0,05)$ para perda de água no descongelamento e perda de água na cocção entre animais controle e animais tratados com 10 ppm de ractopamina.

Embora se esperasse que os animais que receberam ractopamina (ração controle + complexo 2) apresentassem carne mais dura, pois de acordo com Moloney e Beermann, (1996) esse $\beta$ - adrenérgico aumenta o diâmetro das fibras musculares e consequentemente aumenta a resistência ao corte, não foi encontrada diferença $(\mathrm{P}>0,05)$ entre os tratamentos para os valores de força de cisalhamento.

A maciez é tratada como um atributo de textura (BOURNE, 2002), sendo quantificada pela força de cisalhamento. Quanto menor for o valor obtido de força de cisalhamento (kgf), mais macia será a carne.

Segundo Moloney e Beermann (1996), a força de cisalhamento é dependente do nível de inclusão de ractopamina, ou seja, quanto maior for a inclusão, mais dura será a carne.
Quanto aos níveis de vitamina E no músculo $L$. dorsi, houve diferença $(\mathrm{P}<0,05)$ para os tratamentos. Os resultados mostram valores superiores para os tratamentos que têm a vitamina $\mathrm{E}$ associada ou não à ractopamina em relação ao tratamento controle. Estes valores podem valorizar o produto, ou melhorando os aspectos sensoriais e de qualidade da carne, decorrentes de uma menor oxidação, ou como uma fonte desta vitamina diretamente para o consumidor.

$\mathrm{Na}$ Tabela 4, pode-se observar diferença para alguns ácidos graxos presentes na carne de suínos submetidos aos diferentes tratamentos. Para os ácidos graxos saturados, encontrou-se diferença $(\mathrm{P}<0,05)$ nos ácidos graxos pentadecanóico (15:0) e beênico (22:0), que se apresentaram mais baixos nos animais que receberam ração controle e maiores quantidades nos que receberam ração com antioxidante. Houve diferença também para os ácidos graxos monoinsaturados palmitoléico (16:1n-5) e o poliinsaturado linolênico (18:3n-ttc), onde os maiores valores foram encontrados nos animas que receberam ração controle e os menores nos animais que receberam ração com antioxidante, associado ou não à ractopamina. $\mathrm{O}$ ácido graxo linolênico (C18:3) é essencial para a saúde humana. No entanto, apresenta menor ponto de fusão e maior risco de peroxidação da gordura com a formação de flavour mais intenso (CIFUNE et al., 2000). Todavia, o efeito negativo da peroxidação só ocorre na presença de grande quantidade deste ácido graxo. A dieta pode alterar a concentração de C18:3 (COOPER et al., 2004).

A utilização de antioxidantes na dieta é uma das estratégias para diminuir a rancidez oxidativa que pode ser ocasionada pela maior quantidade de ácidos graxos insaturados presentes na carne suína. Portanto, a menor presença desses componentes na carne dos animais que receberam rações com antioxidante pode estar relacionada à menor oxidação observada. 
Tabela 4. Análise do perfil dos ácidos graxos (g/100g), do músculo Longissimus dorsi, de suínos submetidos aos tratamentos experimentais.

\begin{tabular}{|c|c|c|c|c|c|c|}
\hline \multirow{2}{*}{$\begin{array}{l}\text { Ácidos } \\
\text { Graxos }\end{array}$} & \multicolumn{3}{|c|}{ Tratamentos } & \multicolumn{2}{|c|}{ Sexo } & \multirow{2}{*}{$\begin{array}{l}\mathrm{CV} \\
(\%)\end{array}$} \\
\hline & $\begin{array}{c}\text { Ração } \\
\text { Controle }^{1}\end{array}$ & $\begin{array}{l}\text { Ração Controle } \\
+ \text { Complexo } 1^{2}\end{array}$ & $\begin{array}{l}\text { Ração Controle } \\
+ \text { Complexo } 2^{3}\end{array}$ & Macho & Fêmea & \\
\hline AGS & 0,7022 & 0,6066 & 0,5402 & 0,5017 & 0,6916 & 38,24 \\
\hline $14: 0$ & 0,0186 & 0,0174 & 0,0088 & 0,0133 & 0,0157 & 57,59 \\
\hline $15: 0$ & $0,0010 \mathrm{~b}$ & $0,0008 \mathrm{ab}$ & $0,0003 \mathrm{a}$ & 0,0008 & 0,0006 & 47,96 \\
\hline $16: 0$ & 0,4153 & 0,4733 & 0,2976 & 0,3788 & 0,4054 & 45,14 \\
\hline 17 & 0,0041 & 0,0050 & 0,0028 & 0,0035 & 0,0042 & 42,13 \\
\hline $18: 0$ & 0,2003 & 0,2588 & 0,1989 & 0,2334 & 0,2112 & 48,46 \\
\hline $20: 0$ & 0,0062 & 0,0132 & 0,0007 & 0,0108 & 0,0037 & 144,63 \\
\hline 21:0 & 0,0056 & 0,0136 & 0,0081 & 0,0046 & 0,0130 & 88,78 \\
\hline $22: 0$ & $0,0407 \mathrm{~b}$ & $0,0192 \mathrm{ab}$ & $0,0177 \mathrm{a}$ & 0,0173 & 0,0304 & 48,35 \\
\hline $23: 0$ & 0,0011 & 0,0011 & 0,0020 & 0,0014 & 0,0015 & 67,62 \\
\hline $24: 0$ & 0,0097 & 0,0051 & 0,0054 & 0,0052 & 0,0075 & 39,89 \\
\hline AGMI & 0,7140 & 0,9728 & 0,6844 & 0,8083 & 0,7865 & 44,56 \\
\hline $16: 1 n-5$ & $0,0032 \mathrm{a}$ & $0,0016 \mathrm{~b}$ & $0,0022 \mathrm{ab}$ & 0,0021 & 0,0024 & 27,64 \\
\hline $16: 1 n-7$ & 0,0535 & 0,0508 & 0,0296 & 0,0377 & 0,0487 & 47,42 \\
\hline $17: 1 n-10$ & 0,0029 & 0,0029 & 0,0019 & 0,0023 & 0,0027 & 54,33 \\
\hline $18: 1 n-9 t$ & 0,0030 & 0,0019 & 0,0024 & 0,0022 & 0,0025 & 32,78 \\
\hline $18: 1 n-9 c$ & 0,7179 & 0,9089 & 0,6439 & 0,7564 & 0,7622 & 45,39 \\
\hline $18: 1 n-7$ & 0,0021 & 0,0015 & 0,0019 & 0,0014 & 0,0021 & 57,41 \\
\hline $20: 1 n-9$ & 0,0037 & 0,0021 & 0,0021 & 0,0032 & 0,0021 & 41,56 \\
\hline AGPI & 0,2037 & 0,1284 & 0,1254 & 0,1165 & 0,1731 & 39,25 \\
\hline $18: 2 \mathrm{n}-\mathrm{ct}$ & 0,0008 & 0,0009 & 0,0007 & 0,0007 & 0,0009 & 124,04 \\
\hline $18: 2 \mathrm{n}-\mathrm{tc}$ & 0,0009 & 0,0017 & 0,0009 & 0,0016 & 0,0009 & 48,26 \\
\hline $18: 2 n-6$ & 0,1766 & 0,1281 & 0,1005 & 0,1040 & 0,1532 & 37,64 \\
\hline $18: 3 n-6$ & 0,0009 & 0,0018 & 0,0012 & 0,0016 & 0,0011 & 66,39 \\
\hline $18: 3 \mathrm{n}-\mathrm{tct}$ & 0,0013 & 0,0008 & 0,0024 & 0,0025 & 0,0008 & 134,30 \\
\hline $18: 3 n-c c t$ & 0,0007 & 0,0020 & 0,0020 & 0,0014 & 0,0017 & 86,90 \\
\hline $18: 3 \mathrm{n}-\mathrm{ttc}$ & $0,0056 \mathrm{a}$ & $0,0009 \mathrm{~b}$ & $0,0025 \mathrm{ab}$ & 0,0043 & 0,0017 & 71,89 \\
\hline $18: 3 n-3$ & 0,013 & 0,0087 & 0,0134 & 0,0132 & 0,0107 & 41,24 \\
\hline $24: 4 n-9$ & 0,0034 & 0,0018 & 0,0019 & 0,0017 & 0,0027 & 47,39 \\
\hline$\omega 3$ & 0,0187 & 0,0124 & 0,0192 & 0,0203 & 0,0139 & 43,91 \\
\hline$\omega 6$ & 0,1785 & 0,1338 & 0,1032 & 0,1083 & 0,1561 & 36,76 \\
\hline trans & 0,0092 & 0,0082 & 0,0104 & 0,0108 & 0,0081 & 34,96 \\
\hline
\end{tabular}

Médias seguidas de letras diferentes na mesma coluna indicam diferença no teste de Tukey $(\mathrm{P}<0,05)$.

AGS = Ácidos Graxos Saturados; AGM= Ácidos Graxos Monoinsaturados; AGP = Ácidos Graxos Poli-insaturados.

${ }^{1}$ Ração controle (isenta dos complexos), ${ }^{2}$ Ração controle + complexo $1(400 \mathrm{mg}$ de vitamina E $+100 \mathrm{mg}$ de vitamina C/ kg de ração) e ${ }^{3}$ Ração controle + complexo 2 (200 mg de vitamina E + $100 \mathrm{mg}$ de vitamina C + 10 ppm de ractopamina / kg de ração).

Fonte: Elaboração dos autores.

\section{Conclusões}

A inclusão de ractopamina (10 ppm), juntamente com as vitaminas E e C, durante 28 dias, para suínos em fase de terminação, resultou no incremento das características de desempenho e de carcaça. A suplementação com os antioxidantes (vitamina $\mathrm{E}+$ vitamina $\mathrm{C}$ ) determinou melhora da qualidade da carne com diminuição da oxidação lipídica. 


\section{Referências}

AGOSTINI, P. S.; PACHECO, G. D.; SILVA, R. A. M.; YWAZAKI, M. S.; LOZANO, A. P.; VINOKUROVAS, S. L.; DALTO, D. B.; TARSITANO, M. A.; SILVA, C. A.; BRIDI, A. M. Qualidade de carne associada aos parâmetros fisiológicos e sanguíneos de suínos submetidos a diferentes níveis de ractopamina. In: PORKEXPO E FÓRUM INTERNACIONAL DE SUINOCULTURA, 4., Curitiba, 2008. Anais... Curitiba, 2008. p. 106-107.

ARAÚJO, J. M. A. Antioxidantes. In: de alimentos. 3. ed. Viçosa : UFV, 2004. p. 69-99.

ASSOCIAÇÃO BRASILEIRA DE CRIADORES DE SUÍNOS - ABCS. Método brasileiro de classificação de carcaças. 2. ed. Rio Grande do Sul: Estrela, 1973. 17 p.

BLIGH, E.; DYER, W. J. A rapid method of total lipid extraction and purification. Canadian Journal of Bioquemistry, Sherbrooke, v. 37, n. 8, p. 911-917, 1959.

BOCCARD, R.; BUCHTER, L.; CASSELS, E.; COSENTINO, E.; DRANSFIELD, E.; HOOD, D.; JOSEPH, R.; MAC DOUGALL, D.; RHODES, D.; SCHON, I.; TINBERGEN, B. J. TOURAILEE. C. Proceedings for measuring meat quality characteristics in beef production experiments. Livestock Prodution Science, Amsterdam, v. 8, n. 5, p. 385-397, 1981.

BOURNE, M. C. Food texture and viscosity: concept and measurement. 2. ed. San Diego: Academic Press, 2002. $436 \mathrm{p}$.

BOUTON, P. E.; HARRIS, P. V.; SHORTHOSE, W. R. Effect of ultimate $\mathrm{pH}$ upon the water-holding capacity and tenderness of mutton. Journal of Food Science, Chicago, v. 36, n. 3, p. 435-439, 1971.

BRIDI, A. M.; NICOLAIEWSKY, S.; RUBENSAN, J. M. Efeito do genótipo halotano e de diferentes sistemas de produção na qualidade da carne suína. Revista Brasileira de Zootecnia, Viçosa, MG, v. 32, n. 6, p. 13621370, 2003.

BRIDI, A. M.; OLIVEIRA, A. R.; FONSECA, N. A.; SHIMOKOMAKI, M.; COUTINHO, L. L.; SILVA, C. A. Efeito do genótipo halotano, da ractopamina e do sexo do animal na qualidade da carne suína. Revista Brasileira de Zootecnia, Viçosa, MG, v. 35, n. 5, p. 2027-2033, 2006.

BRIDI, A. M.; SILVA, C. A. Avaliação da carne suína. 2. ed. Londrina: Midiograf, 2009. 120 p.

BRIDI, A. M.; SILVA, C. A; SHIMOKOMAKI, M. Uso da ractopamina para o aumento de carne na carcaça do suíno. Revista Nacional da Carne, São Paulo, v. 1, n. 307, p. 91-94, 2002.
BRUBACHER, G.; MULLER-MULOT, W.; SOUTHGATE, D. A. T. Methods for the determination of vitamins in food. London: Elsevier Applied Science Publishers, 1985. $166 \mathrm{p}$.

BUDIÑO, F. E. L.; THOMAZ, M. C.; RUIZ, U. S.; FRAGA, A. L. F.; HUAYNATE, R. A. R.; NETO, A. C.; SANTOS, V. M. Desempenho e características de carcaça de suínos em terminação recebendo diferentes níveis e marcas comerciais de cloridrato de ractopamina. Boletim de Indústria Animal, Nova Odessa, v. 62, n. 3, p. 245-250, 2005.

CANNON, J. E.; MORGAN, J. B.; SCHMIDT, G. R.; TATUM, J. D.; SOFOS, J. N.; SMITH, G. C.; DELMORE, R. J.; WILLIAMS, S. N. Growth and fresh meat quality characteristics of pigs supplemented with vitamin E. Journal of Animal Science, Chicago, v. 74, n. 1, p. 98-105, 1996.

CARDOSO, L. A.; STOCK, M. J. Effect of clenbuterol on growth and body composition during food restriction in rats. Journal of Animal Science, Chicago, v. 74, n. 9, p. 2245-2252, 1996.

CARR, S. N.; IVERS, D. J.; ANDERSON, D. B.; JONES, D. J.; MOWREY, D. H.; ENGLAND, M. B.; KILLEFER, J.; RINCKER, P. J.;MCKEITH, F. K. The effects of ractopamine hydrochloride on lean carcass yields and pork quality characteristics. Journal of Animal Science, Chicago, v. 83, n. 12, p. 2886-2893, 2005.

CHEAH, K. S.; CHEAH, A. M.; KRAUSGRILLE, D. I. Effect of dietary supplementation of vitamin E on pig meat quality. Meat Science, Barking, v. 39, n. 2, p. 255264, 1995.

CIFUNE, G. F.; NAPOLITANO, F.; PACELLI, C.; RIVIEZZI, A. M.; GIROLAMI, A. Effect of age at slaughter on carcass traits, fatty acid composition and lipid oxidation of Apulian lambs. Small Ruminant Research, London, v. 35, n. 1, p. 65-70, 2000.

COOPER, S. L.; SINCLAIR, L. A.; WILKINSON, R. G.; HALLETT, K. G.; ENSER, M.; WOOD, J. D. Manipulation of the n-3 polyunsaturated fatty acid content of muscle and adipose tissue in lambs. Journal of Animal Science, Chicago, v. 82, n. 5, p. 1461-1470, 2004.

CRACKEL, R. L.; GRAY, I. J.; PEARSON, A. M.; BOOREN, A. M.; BUCKLEY, D. J. Some further observations on the TBA test as an index of lipid oxidation in meats. Food Chemistry, London, v. 28, n. 3 , p. 187-196, 1988.

EIKELENBOOM， G.; HOVING-BOLINK, A. H.; KLUITMAN, I.; HOUBEN, J. H.; KLONT, R. E. Effect of dietary vitamin $\mathrm{E}$ supplementation on beef colour stability. Meat Science, Barking, v. 54, n. 1, p. 17-22, 2000. 
GIRÃO,L.V.C.; RESENDE,A. E.; CANTARELLI, V. S.; FERREIRA, L. V.; CARVALHO JÚNIOR, F. M.; SILVA, C. T. C.; LIMA, J. A. F.; FERREIRA, M. A. Desempenho de suínos pesados, machos castrados e fêmeas, durante o 14 e 28 dias de suplementação com ractopamina. In: PORKEXPO E FÓRUM INTERNACIONAL DE SUINOCULTURA, 4., 2008, Curitiba. Anais... Curitiba, 2008. p. 139-141.

HASTY, J. L.; VAN HEUGTEN, E.; SEE, M. T.; LARICK, D. K. Effect of vitamin E on improving fresh pork quality in Berkshire- and Hampshire-sired pigs. Journal of Animal Science, Chicago, v. 80, n. 12, p. 32303237, 2002.

HOVING-BOLINK, A. H.; EIKELEMBOOM, G.; VAN DIEPEN, J. T. M.; JONGBLOED, A. W.; HOUBEN, J. H. Effect of dietary vitamin E supplementation on pork quality. Meat Science, Barking, v. 49, n. 2, p. 205-212, 1998.

LAWRIE, R. A. Ciência da carne. 6. ed. Porto Alegre: Artmed, 2005. 384 p.

MARCHANT-FORDE, J. N.; LAY JÚNIOR, D. C.; PAJOR, E. A.; RICHERT, B. T.; SCHINKEL, A. P. The effects of ractopamine on the behavior and physiology of finishing pigs. Journal of Animal Science, Chicago, v. 81, n. 2, p. 416-422, 2003.

MOLONEY, A. P.; BEERMANN, D. H. Mechanisms by with $\beta$-adrenergic agonists alter growth and body composition in ruminants. In: ENNE, G.; KUIPER, H. A.; VALENTINI, A. Residues of veterinary drugs and mycotoxins in animal products. Wageningen: Wageningen Pers, 1996. p. 124-136.

MORRISSEY, P. A.; SHEEHY, P. J. A.; GALVIN, K.; KERRY, J. P.; BUCKLEY, D. J. Lipid stability in meat and meat products. Meat Science, Barking, v. 49, n. 1, p. 73-86, 1998.

NATIONAL RESEARCH COUNCIL - NRC. Nutrient requirements of swine. 10. ed. Washington: National Academy Press, 1998.
ONIBI, G. E.; SCAIFE, J. R.; MURRAY, I.; FOWLER, V. R. Use of $\alpha$-tocopherol acetate to improve fresh pig meat quality of full-fat rapeseed-fed pigs. Journal of the American Oil Chemists Society, Madison, v. 75, n. 2, p. 189-198, 1998.

PALERMO-NETO, J. Agonistas de receptores b2adrenérgicos e produção animal. In: SPINOSA, H. S.; GÓRNIAK, S. L.; BERNARDI, M. M. Farmacologia aplicada à medicina veterinária. 3. ed. Rio de Janeiro: Guanabara Koogan, 2002. v. 1, p. 807-813.

PENNY, P. Elevação dos teores de DHA ômega-3 e selênio na carne suína: agregando valor para consumidores e produtores. Porkworld, São Paulo, v. 1, n. 22, p. 66-69, set./out. 2004.

RADCLIFFE, J. S. A importância dos modificadores de carcaça suína para a qualidade da carne. Porkworld, São Paulo, v. 1, n. 22, p. 50-54, set./out. 2004.

SOARES, A. L.; MARCHI, D. F.; MATSUSHITA, M.; GUARNIERI, P. D.; DROVAL, A. A.; IDA, E. I.; SHIMOKOMAKI, M. Lipid oxidation and fatty acid profile related to broiler breast meat color abnormalities. Brazilian Archivies of Biology and Technology, Curitiba, v. 52, n. 6, p. 1513-1518, 2009.

SOUZA, V. L. F. A influência de dietas suplementadas com vitamina $E$ desde o crescimento e terminação do suíno até o presunto cozido no seu período de validade: índices zootécnicos, estabilidade oxidativa, perfil de ácidos graxos, colesterol e óxidos de colesterol. 2001. Tese (Doutorado em Ciência de Alimentos) - Curso de Pós-Graduação em Ciência de Alimentos. Universidade Estadual de Londrina, Londrina.

TARLADGIS, B. G.; PEARSON, A. M.; DUGAN JÚNIOR, L. R. Chemistry of 2- thiobarbituric test for determination of oxidative rancidity in foods. II. Formation of the TBA- malonaldehyde complex without acid-heat treatment. Journal of Food Science and Agriculture, Malden, v. 5, n. 9, p. 602-604, 1964.

UNIVERSIDADE FEDERAL DE VIÇOSA - UFV. Sistema de análises estatísticas e genéticas - SAEG. Versão 7.1. Viçosa, MG, 1997. 150 p. 